\title{
Are nematodes costly to fig tree-fig wasp mutualists?
}

by Rong-Rong, S., Miao, B., Segar, S.T., Zeng, Y., Wang, B. and Peng, Y.

Copyright, publisher and additional information: this is the author accepted manuscript. The final published version (version of record) is available online via Wiley. This article may be used for non-commercial purposes in accordance with Wiley Terms and Conditions for Self-Archiving.

Please refer to any applicable terms of use of the publisher.

DOI: https://doi.org/10.1111/eea.12860 


\section{Title page}

\section{Are nematodes associated with fig-fig wasp mutualism detrimental?}

Rong-Rong Shi ${ }^{1,2}$, Bai-Ge Miao ${ }^{1}$, Simon T. Segar ${ }^{3,}$, 5 , Yongsan Zeng ${ }^{6}$, Bo Wang $^{1,2 *}$, Yan-Qiong Peng ${ }^{1,2 *}$

1. CAS Key Laboratory of Tropical Forest Ecology, Xishuangbanna Tropical Botanical Garden, Chinese Academy of Sciences, Menglun 666303, China.

2. Center for Plant Ecology, Core Botanical Gardens, Chinese Academy of Sciences, Mengla, Yunnan 666303, China.

3. Laboratory of Evolutionary Ecology, Department of Ecology, Institute of Entomology, Biology Centre CAS, Ceske Budejovice, 37005, Czech Republic.

4. Biology Centre of the Czech Academy of Sciences, Institute of Entomology, Ceske Budejovice, Czech Republic.

5. Department of Crop and Environment Sciences, Harper Adams University, Newport, Shropshire, UK, TF10 8NB

6. Department of Plant Protection, Zhongkai University of Agriculture and Engineering, Guangzhou510225, China.

* Correspondence and requests for materials should be addressed to B. W. and P.Y.-Q. (Email: wangbo@xtbg.ac.cn; pengyq@xtbg.ac.cn)

Running title: Parasitic nematodes in fig-fig wasp mutualism 
11 in two seasons and two developmental stages of figs in Xishuangbanna, China. We

12 followed this up by quantifying the effects of nematodes on fitness related traits on fig

13 wasps (e.g. egg loads, pollen grains, and longevity) and fig trees (seed production) in

14 gynodioecious $F$. hispida. The magnitude of nematode infection was compared between

15 pre- and post- dispersal pollinators to quantify the probability of nematodes being

16 transported to new hosts. Our results showed that Ficophagus microcarpus was the only

17 nematode in Ficus microcarpa. In Ficus hispida, Martininema guangzhouensis was

18 the dominant nematode species, while Ficophagus centerae was rare. For both

19 species of Ficus, rainy season and inter-floral figs had higher rates of nematode

20 infection than the dry-hot season and receptive figs. Nematodes did not affect the 21 number of pollen grains or egg loads of female wasps. We did not detect a correlation 
22 between seed production and nematode infection. However, carrying nematodes

23 reduced the lifespan and dispersal ability of pollinator wasps, indicating higher rates

24 of post-emergence mortality in infected fig wasps. Severely infected fig wasps were

25 likely 'filtered out', preventing the overexploitation of figs by wasps and stabilizing

26 the interaction over evolutionary time.

27 Keywords: Ficus, Agaonidae, mutualism, nematodes, coexistence 


\section{Introduction}

Life on earth is embedded in a complex network of interactions, with mutually

beneficial connections forming the backbone of most high diversity ecosystems

31 (including but not limited to coral reefs and tropical rainforests) (Bascompte \& Jordano,

32 2007). Such widespread and inherently stable interactions are often exploited by third-

33 party parasites (Lee, 2015; Sachs \& Simms, 2006), which pose a serious threat for

34 mutualistic species (Sachs \& Simms, 2006). While exploitative parasites may render

35 the costs accrued by one or both mutualists to be evolutionarily unstable, a long-term

36 exploitation strategy should result in a moderate or variable level of costs to each

37 mutualist. Investigating the evolutionary significance of parasites is difficult, not least

because most collapsed mutualisms are not possible to detect, but also because we must combine theoretical and empirical approaches in tractable systems if we are to progress.

Fig trees (Ficus spp.) and their pollinating wasps (Hymenoptera: Agaonidae) represent a well-known obligate mutualism (Weiblen, 2002; Wiebes, 1979). Each Ficus species relies on an obligate fig wasp to pollinate, and in return the trees provide nutrition and space for wasp larvae to develop inside enclosed inflorescences ('figs') (Weiblen, 2002). Individual figs go through several developmental stages, these include 'A phase' (pre-female flowers), 'B phase' (female flowers), 'C phase' (interfloral), 'D phase' (male flowers), and 'E phase' (postfloral), over a period of several weeks or months (Galil \& Eisikowitch, 1968). The pollinating wasps enter receptive figs (B phase) through a specialized entrance to pollinate and oviposit in female flowers within. 
49 Offspring of fig wasps will develop in C stage figs until they emerge (D phase), at

50 which point alate female pollinator wasps leave the figs from channels bored by

51 apterous male wasps to search for new receptive hosts and the life cycle anew.

52 In addition to obligate mutualistic pollinators, many other organisms live in the

53 figs (enclosed inflorescences) (Borges, 2015), including various species of nematodes

54 (Giblin-Davis et al., 1995; Kerdelhue et al., 2000; Van Goor et al., 2018). More than

5520 species of nematodes associated with Ficus in the genus Schistonchus are described

56 and are largely considered as plant parasites that lead to reduced growth of the florets

57 and indirectly reduced seed production (Davies et al., 2015). Schistonchus sensu stricto

58 was redefined to include two new genera Ficophagus and Martininema in 2015, and 18

59 Ficophagus spp., and 3 Martininema spp. have been described (Davies et al., 2017a;

60 Davies et al., 2015; Davies et al., 2017b). Another genus, Parasitodiplogaster, is

61 thought to consist of fig-wasp-parasitic nematodes (Giblin-Davis et al., 2006; Herre,

62 1993; Herre, 1995; Ramirez, 1974; Van Goor et al., 2018). Although these nematodes

63 are specifically detected in Ficus and their fig wasps, the exact (facultative or obligate)

64 association between nematodes and Ficus species is not usually established (Giblin-

65 Davis et al., 1995).

66

The life history of nematodes is closely matched with both figs and fig wasps (Van

67 Goor et al., 2018). In D phase, when the fig becomes mature, infective juvenile

68 nematodes aggregate in the cavity of figs ready to infect newly emerged pollinating fig

69 wasps (Krishnan et al., 2010; Martin et al., 1973). Once they contact the newly emerged 
70 wasps, nematodes quickly enter the body of wasps through trachea in the thoracic or

71 abdominal cavities (Poinar \& Herre, 1991). Nematodes are then carried by female fig

72 wasps to new receptive figs, laying eggs in the host and starting their life cycle anew.

73 Approximately half of all Ficus species are monoecious and the remainder are

74 gynodioecious (Janzen, 1979). In monoecious Ficus species, one fig can produce both

75 pollens and seeds. Pollinating fig wasps and nematodes also live within the figs.

76 When the new generation of pollinating fig wasps emerge, they carry nematodes to

77 new figs such that the nematodes have the potential to disperse from every fig

78 However, in gynodioecious Ficus species, female trees produce viable seeds

79 (functionally female) and male trees produce pollens and support the development of

80 fig wasps (functionally male) (Weiblen, 2002). Nematodes in female gynodioecious

81 figs cannot disperse to a new fig as wasps are not produced. Therefore, the costs

82 incurred by nematodes in female gynodioecious figs are considerably greater. Any costs

83 inflicted on figs through nematode presence (e.g. consumption of fig or wasp tissue)

84 will also differ, reducing pollen dispersal in male figs and seed production in female

85 figs. Moreover, because fig wasp populations and fig phenology are variable across

86 seasons (Wang et al., 2019a; Wang \& Sun, 2009), we hypothesise that corresponding

87 seasonal variation also exists for nematode prevalence, but that this is more pronounced

88 in gynodioecious figs which have increased seasonal constraints on production. We also

89 predict higher abundance of nematodes on gynodioecious figs because half of all

90 vectored nematodes will languish in female figs. 

nematode abundance may also vary with floret development (corresponding to fig development), which may allow multiple nematodes to co-exist within one individual syconium (Center et al., 1999). Seasonal variation in Schistonchus nematode abundance could also be linked to seasonal dynamics in fig wasps (Davies et al., 2010). However, Parasitodiplogaster species have been reported to develop inside wasps and use the syconia as repositories for the dauer (dispersal stage of nematodes) juveniles (Herre, 1996; Poinar \& Herre, 1991; Van Goor et al., 2018), meaning that their presence can

100 influence pollinating wasp longevity, host location and pollination efficiency; and

101 indirectly seed production in fig trees. The biology and impact of nematodes on the fig-

102 fig wasp mutualism remains under studied, with most studies focusing on the taxonomy,

103 diversity, and phylogeny of nematodes (Davies et al., 2015; Sun et al., 2017; Susoy et 104 al., 2016; Zeng et al., 2011).

105 Figs, fig wasps and their parasitic nematodes provide a comparative system for 106 assessing the influence of third parties on mutualism persistence and the cost of 107 parasitism (Dunn et al., 2008a; Herre et al., 1999; Van Goor et al., 2018; Wang et al., 108 2019b). However, the effects of nematodes on the fig-fig wasp mutualism are not 109 always clear (but see (Van Goor et al., 2018)). In this study, we conducted both field 110 surveys and field experiments to answer the following questions: (1) What is the 111 pattern of nematode occurrence across different seasons in Xishuangbanna, in 
112 different fig developmental stages and in different fig wasp life stages? (2) What are

113 the effects of phoretic nematodes on pollinating wasp-fig fitness? (3) Can phoretic

114 nematodes impact the ability of fig wasps to act as effective pollinators?

115 


\section{Materials and methods} pollinated by Ceratosolen solmsi marchali in Xishuangbanna (Peng et al., 2005). The

132 plant parasitic nematodes Ficophagus centerae and Martininema guangzhouensis

133 were found in the figs of F. hispida (Davies et al., 2015; Zeng et al., 2007). However,

134 in our study, M. guangzhouensis is the dominant species, and F. centerae is rare, 135 making up only $0.5 \%$ of the nematode records. 
137 developing fig wasp larvae, while the figs on female trees contain only female flowers

138 which produce seeds. Contrasting phenology and dispersal dynamics of monoecious

139 and gynodioecious fig species lead to distinct expectations in terms of nematode

140 abundance and fitness costs. For example, because female figs represent reproductive

141 dead ends to nematodes there is likely to be stronger selection for rapid reproduction

142 and population growth (and higher overall abundance) in colonizing nematodes in

143 colonizing nematodes of gynodioecious figs.

146 We sampled $\mathrm{C}$ phase figs to check whether they were infested by nematodes. The

147 figs were collected from the monoecious $F$. microcarpa, as well as male and female

148 trees of gynodioecious $F$. hispida. Each type of sample was collected from 10 trees, and

149100 fruits were collected per tree. The sampled figs were surface cleaned before each

150 fig was cut into small pieces and put in Petri dish with distilled water. The nematodes

151 (juveniles and adults) entered the water after 2-4 h, after which we confirmed their

152 presence under a stereoscope (LeicaS8AP0). The figs with and without nematodes were

153 recorded.

154 Experiment 2: Variation of nematode abundance in different seasons and fig developmental phases

156 Nematodes are transported by fig wasps to new figs. During A stage, there are no 
157 fig wasps inside the figs, therefore no nematodes were detected in the figs in the

158 preliminary observations. In $\mathrm{D}$ phase, both fig wasps and nematodes are mature and

159 ready for dispersal. Therefore, we sampled post-pollination B phase figs as well as late

$160 \mathrm{C}$ phase figs as a means of investigating nematode abundance in the hot-dry season

161 (lasting from March to April) and the rainy season (lasting from May to August).

162 Similarly, B and C phase figs were also collected from the monoecious $F$. microcarpa,

163 as well as male and female trees of gynodioecious $F$. hispida. Each type of sample was

164 collected from 10 trees, and 30 fruits were collected from each tree. The Baermann

165 funnel method was used to collect nematodes from figs (Staniland, 1954); each fruit

166 was cut into small pieces that were placed in a funnel with a thin filter paper and

167 distilled water. The nematodes entered the water and sank into a latex tube linked to the

168 funnel, which was controlled by a flat jaw pinchcock. After 4-8 h, the water with

169 nematodes was collected, and the nematodes were identified to species and counted

170 (both juveniles and adults) under a stereoscopic microscope (Leica DM2000 and

171 LeicaS8AP0).

172 Experiment 3: Nematode infection in different stages of adult pollinating fig

173 wasps

174 We collected figs near D phase from male trees of $F$. hispida to observe nematode

175 activity. Four different stages of pollinators were obtained, including unmated

176 individuals in closed galls (unmated), mated individuals in galls (mated), and

177 individuals both inside (before emergence) and outside figs during D phase (emerged). 
178 Figs were cut open in a mesh bag to prevent emerged wasps from escaping. Unexited

179 galls were dissected to obtain unmated female pollinators, while mated pollinators were

180 obtained from galls with mating holes. All wasps inside the fig cavities were collected

181 with tweezers. Wasps (outside the figs) flying around B phase figs were caught with a

182 mesh net in the field. These female pollinators were dissected in distilled water in a

183 petri dish and the nematodes were counted under a stereoscopic microscope

184 (LeicaS8AP0). Three male trees were sampled and we collected five figs per tree, while

185 ten wasps were randomly selected per fig for each stages (unmated, mated, before

186 emergence, emerged) of adult pollinating fig wasps.

187

Experiment 4: Effects of nematodes on the amount of pollen carried by fig-

189

190

191

192

193

194

195

196

197

198 pollinating wasps and their egg loads

The figs in D phase were collected from male trees of $F$. hispida and placed in mesh bags, and the fig wasps that naturally emerged from the figs and female pollinators were collected. Eleven figs were collected from four trees, and we randomly selected 10-30 female pollinators from each fig. In total, 150 female pollinators were examined. We detached the abdomen of each female pollinating wasp in a petri dish filled with distilled water using fine entomological pins. Following this we dissected the ovary, separated each ova, and then counted the number of ova and nematodes under a stereoscopic microscope (LeicaS8AP0) according to Dunn et al (2011).

The pollen grains carried inside the pollen pockets of each wasp were quantified. 
199 We removed the pollen pockets of wasps with dissecting needles under a stereoscopic 200 microscope (LeicaS8AP0) and then placed them into a $1.5 \mathrm{ml}$ centrifuge tube with $0.5 \mathrm{ml}$ 201 of electrolyte solution $(0.9 \% \mathrm{NaCl})$. The tubes were placed into an ultrasonic bath 202 (SK1200H, Shanghai KUDOS Ultrasonic Instrument CO., LTD) for 60 seconds to 203 detach the pollen grains. Each sample was brought to a total volume of $80 \mathrm{ml}$ with 204 electrolyte solution and pollen grains were counted using a particle counter 205 (Multisizer $^{\mathrm{TM}} 3$ COULTER COUNTER ${ }^{\circledR}$, Beckman Coulter Inc., Brea, CA). We ran 206 each sample three times and calculated the average (Simón-Porcar et al., 2014). Experiment 5: Comparing the lifespan of wasps with and without nematodes The D phase figs were collected from male trees of $F$. hispida to capture female pollinators that naturally emerged from the figs. About 50 female pollinators emerging

210 from the same fig were placed into a plastic bottle $(3 \mathrm{~cm}$ in diameter and $5 \mathrm{~cm}$ high), and

211 a wet filter paper was placed in the bottom to maintain moisture. The bottles were kept 212 at room temperature (around $25^{\circ} \mathrm{C}$ ) and approximately $75 \%$ humidity in a natural 213 light/dark cycle. They were checked every two hours and the dead female pollinators 214 were removed and counted (Dunn et al., 2008b). Wasps were then dissected and the 215 number of nematodes was recorded once all were dead. In total, eight bottles of wasps 216 (364 female pollinators, 97 with and 267 without nematodes) were monitored. Experiment 6: Nematodes carried by fig-pollinating wasps and the effects on wasp

218 dispersal

219 Nematodes were collected from 'newly emerged' wasps and those wasps that had 
220 'arrived' in the B phase figs. For 'newly emerged' wasps, we collected ten figs in the D

221 phase from each of two male trees of $F$. hispida. Each fig was placed into a mesh bag

222 during wasp emergence. Ten wasps were collected from each fig, a total 200 wasps

223 were used to count and measure nematodes. For 'arrived' wasps, we collected the female

224 wasps flying around the B phase figs of three $F$. hispida trees. In total, 143 female

225 wasps were collected, approximately 50 wasps per tree. Fig wasps were immediately

226 dissected to count the nematodes in the ovary, and the body lengths of the nematodes

227 were measured with a stereoscopic microscope (LeicaS8AP0) with a micrometer.

Experiment 7: The impact of nematode infection on seed production

The relationship between the number of nematodes and fig seeds was studied as

230 follows. Three female trees of $F$. hispida were sampled, about ten figs in which the

231 seeds were close to maturity were randomly selected and subsequently cut into small

232 pieces. All the seeds were removed and the pieces were placed into a glass funnel with

233 distilled water. The funnel was placed on a layer of mesh bags to prevent the seeds from

234 falling into the bottom of the funnel. After two to four hours the nematodes had moved

235 to the bottom of the funnel, after which we transferred them into a Petri dish and

236 quantified their abundance. The seeds on the mesh bags were dried at room temperature

237 and then counted.

$238 \quad$ Data analysis

239 In F. hispida, M. guangzhouensis was the dominant species and F. centerae was

240 rare species in our samples, making up less than $0.5 \%$ of the nematode individuals 
241 sampled. Thereafter, the nematode abundance represented the abundance of $M$. 242 guangzhouensis in the following analysis.

246 The null hypothesis was that the proportion of nematode occurrences was equal for

247 the two tree species. The same analysis was used to compare occurrence and 248 frequency between female and male trees of F. hispida.

Experiment 2: Variation of nematode abundance in different seasons and fig developmental phases

251 Nematode abundance data were analyzed using a zero-inflated general linear 252 mixed model (ZIFGLMM) to account for the high number of zeros in the data set 253 (Brooks et al., 2017; Zuur et al., 2009). In this analysis, data were modeled as coming 254 from two different processes: the binomial process and the counting process. Then, a 255 binomial generalized linear mixed model (GLMM) was used to determine the 256 probability of measuring a zero; see below for the covariates included in these models.

257 A Poisson or negative binomial GLMM modeled the counting process, and we used a 258 backward stepwise strategy to select the best model for these data according to the 259 Akaike information criterion (AIC). Likelihood ratio tests were used to quantify the 260 effects of each explanatory variable by dropping each variable in turn and comparing 261 the results to the whole model. (Zar, 1999). 
263 'developmental phase' was set as fixed variables, and 'tree' was a random effect. For $F$.

264 hispida, nematode number was the response variable, and 'season' (two levels: 'hot-dry'

265 and 'rainy'), 'developmental phase' (two levels: 'B phase' and 'C phase'), 'sex of the tree'

266 (two levels: 'male' and 'female'), and 'tree' (ten levels) were set as explanatory variables.

267 Experiment 3: Nematode infection in different stages of adult pollinating fig wasps

268 A generalized linear model fitted a Poisson distribution was used to analyze the

269 nematode abundance in different stages (unmated, mated, before emergence, emerged)

270 of adult pollinating fig wasps, and pair-wise multiple comparisons between different

271 stages were performed using the Tukey contrasts.

Experiment 4: Effects of nematodes on the amount of pollen carried by fig-

273 pollinating wasps and their egg loads

Two GLMMs were fitted to test the effects of nematodes on i) the pollen and ii)

275 egg loads of fig-pollinating wasps, including nematode number as a fixed effect and

276 tree as a random effect.

Experiment 5: The lifespan of wasps with and without nematodes

To compare the lifespan of wasps with and without nematodes, we categorized

279 the number of nematodes as either nematode free (no nematodes detected) or with

280 nematodes (more than one nematode detected). Kaplan-Meier survival curves were

281 drawn from the survival time (hours), and the two categories were compared using

282 the Wilcoxon test (Therneau, 2015). Additionally, a Pearson's product-moment 
283 correlation was used to analyze the relationship between the lifespan of the fig wasps

284 and the number of nematodes they transported.

285 Experiment 6: Nematodes carried by fig-pollinating wasps and their effects on

286 wasp dispersal

287 Welch's two-sample t-tests were used to test for a difference in body length and 288 the number of nematodes between 'newly emerged' and 'arrived' fig wasps.

Experiment 7: The impacts of nematode infection on seed production

Pearson's product-moment correlation was used to test the relationship between

291 the number of nematodes and seeds.

All analyses were conducted in R 3.4.3 (R Development Core Team, 2018) with

293 R packages 'glmmTMB' (Brooks et al., 2017), 'Imtest' (Zeileis \& Hothorn, 2002), and

294 'survival' (Terry, 2015). 


\section{Results} microcarpus different significantly among trees $\left(\chi^{2}=101.04, \mathrm{df}=11, \mathrm{p}<0.001\right)$.

305 female trees being infested. The prevalence of M. guangzhouensis did not differ

306 significantly between male and female trees $\left(\chi^{2}=0.65, \mathrm{df}=1, \mathrm{p}=0.42\right.$, Figure $\left.1 \mathrm{a}\right)$.

307 However, the prevalence of $M$. guangzhouensis differed significantly among trees $308 \quad\left(\chi^{2}=146.32, \mathrm{df}=19, \mathrm{p}<0.001\right)$.

309 The occurrence of M. guangzhouensis in F. hispida was significantly higher than

310 the occurrence of $S$. microcarpus in F. microcarpa (Pearson's Chi-squared test with

311 Yates' continuity correction: $\chi^{2}=1375.4, \mathrm{df}=1, \mathrm{p}<0.001$, Figure $1 \mathrm{~b}$ ).

313 developmental phases

314 For F. microcarpa, the ZIFGLMM failed to converge, this was because there

315 were too many zeros under the levels of the random effect 'tree'. Thus, we excluded 316 the random effect and used a ZIFGLM model in the count model. Significantly more 
318 dry-hot season $\left(\chi^{2}=200.33, \mathrm{df}=1, \mathrm{p}<0.001\right.$, Table 1, Figure 2a). More $S$. microcarpus

319 were detected in $C$ phase than B phase $\left(\chi^{2}=151.51, \mathrm{df}=1, \mathrm{p}<0.001\right.$, Figure $\left.3 \mathrm{a}\right)$.

320 Interactions between season and fig developmental phase were significant

$321\left(\chi^{2}=1419.7, \mathrm{p}<0.001\right.$, Table 1$)$. For the logistic model, both season $\left(\chi^{2}=115.36, \mathrm{df}=1\right.$,

$322 \mathrm{p}<0.001)$ and fig developmental phase $\left(\chi^{2}=13.17, \mathrm{df}=1, \mathrm{p}<0.001\right)$ significantly

323 influenced S. microcarpus abundance.

324 For F. hispida, significantly more M. guangzhouensis were detected in the rainy

325 season than the dry-hot season (count model: $\chi^{2}=5539.90, \mathrm{df}=1, \mathrm{p}<0.001$, Table 1 ,

326 Figure 2b) and more M. guangzhouensis were detected in C phase figs than B phase

327 figs (count model: $\chi^{2}=11833.00, \mathrm{df}=1, \mathrm{p}<0.001$, Table 1, Figure $3 \mathrm{~b}$ ). However, the

328 difference in nematode abundance between sexes was not significant (count model:

$329 \chi^{2}=6.96, d f=3, p=0.07$, Table 1). Interactions among season, sex, and phase were

330 significant $\left(\chi^{2}=14.45, \mathrm{df}=7, \mathrm{p}=0.043\right.$, Table 1$)$. For the logistic model, neither sex

$331\left(\chi^{2}=0.43, \mathrm{df}=1, \mathrm{p}=0.51\right)$ nor season $\left(\chi^{2}=1.71, \mathrm{df}=1, \mathrm{p}=0.19\right)$ significantly affected $M$.

332 guangzhouensis abundance, but fig developmental phase $\left(\chi^{2}=23.82, \mathrm{df}=1, \mathrm{p}<0.001\right)$

333 was significantly related to M. guangzhouensis abundance.

334 The number of nematodes (M. guangzhouensis for $F$. hispida and $M$.

335 guangzhouensis for F. microcarpa) differed significantly between F. hispida and F.

336 microcarpa (Wilcoxon rank test, $\mathrm{W}=5^{*} 10^{5}, \mathrm{p}<0.001$ ), F. hispida had more nematodes

337 per fig than F. microcarpa (Table 1). 
341 appeared in the gall, an average of $7.74 \pm 7.38(\mathrm{n}=50)$ M. guangzhouensis nematodes

342 were able to enter the galls to attack the female wasps. After the wasps entered the fig 343 cavity, an average of $43.90 \pm 36.83$ ( $\mathrm{n}=50)$ M. guangzhouensis infested the bodies of 344 the wasps, finally, an average of $2.58 \pm 2.85$ (n=50) M. guangzhouensis entered the 345 wasp abdomen to leave the natal figs. The analysis of variation in abundance of $M$. 346 guangzhouensis at different fig developmental stages showed a significant difference 347 among the developmental stages of the pollinating fig wasps $\left(\chi^{2}=4297, \mathrm{df}=3\right.$, $348 \mathrm{p}<0.001)$ in F. hispida. Multiple comparisons showed significant differences among 349 'mated', 'before emerged', and 'emerged fig wasps' (Figure 4). Because no 350 nematodes were detected in unmated wasps, these also differed from all other stages.

$351 \quad$ Experiment 4: Effects of nematodes on the amount of pollen carried by fig-

352 pollinating wasps and their egg loads

353 Pollinating fig wasps of F. hispida with M. guangzhouensis carried an average 354 of $796.3 \pm 404.08(\mathrm{n}=70)$ pollen grains and $274.51 \pm 50.61(\mathrm{n}=70)$ eggs. In contrast, 355 nematode-free wasps carried an average of $698.83 \pm 390.58(n=80)$ pollen grains and $356298.44 \pm 64.24(\mathrm{n}=80)$ eggs. Therefore, M. guangzhouensis did not affect pollinating 357 fig wasp pollen grains $\left(\chi^{2}=3.20, \mathrm{df}=1, \mathrm{p}=0.07\right)$ or egg loads $\left(\chi^{2}=1.14, \mathrm{df}=1, \mathrm{p}=0.29\right)$. 
360 lifespan of $23.43 \pm 1.36 \mathrm{~h}(\mathrm{SD}, \mathrm{n}=97)$, while female pollinators without nematodes

361 survived $33.75 \pm 1.49 \mathrm{~h}(\mathrm{SD}, \mathrm{n}=267)$ on average. These results suggest that

362 nematodes significantly reduced fig wasp lifespan $\left(\chi^{2}=130, \mathrm{df}=1, \mathrm{p}<0.001\right.$, Figure 5).

363 Finally, there was a significant negative correlation between fig wasp life span and the

364 number of nematodes carried $(r=-0.41, \mathrm{p}<0.001)$.

365 Experiment 6: Nematodes carried by fig-pollinating wasps and their effects on

366 wasp dispersal

367 The number of M. guangzhouensis carried by 'newly emerged' $(6.38 \pm 5.14, \mathrm{n}=104)$

368 fig wasps and fig wasps that 'arrived' $(1.47 \pm 2.40, \mathrm{n}=100)$ in the $\mathrm{B}$ phase figs differed

369 significantly $(\mathrm{t}=-8.80, \mathrm{df}=147.13, \mathrm{p}<0.001)$. However, the body length of $M$.

370 guangzhouensis did not differ significantly $(\mathrm{t}=-0.28, \mathrm{df}=76.79, \mathrm{p}=0.78)$ between

371 'newly emerged' $(0.063 \pm 0.0066 \mathrm{~mm}, \mathrm{n}=50)$ and 'arrived' $(0.062 \pm 0.0062 \mathrm{~mm}, \mathrm{n}=49)$

372 pollinating fig wasps.

\section{Experiment 7: The impacts of nematode infection on seed production}

374 We sampled 28 female figs in mature phase from three trees of $F$. hispida; only

375 two figs were not infested by M. guangzhouensis. The rest had nematodes, and no

376 correlation was observed between seed production and the number of $M$.

377 guangzhouensis in mature fig fruit $(\mathrm{r}=0.03, \mathrm{p}=0.89)$. 


\section{Discussion}

Although the nematodes (M. guangzhouensis) associated with F. hispida were

380 frequently detected in the figs and transported by pollinating fig wasps, they had no

381 deleterious impact on fig wasp egg loads or the number of pollen grains carried.

382 Martininema guangzhouensis did not develop during the period in which they were

383 carried inside/outside the body of the fig wasps. However, transportation of $M$.

384 guangzhouensis reduced the lifespan of pollinator wasps, and pollinator wasps with

385 more nematodes showed a reduced ability to reach receptive fig trees. Therefore, $M$.

386 guangzhouensis nematodes had limited detrimental effects on either mutualist.

387 However, based on their phylogenetic position, it is likely that these nematodes are

388 fungi feeders (Davies et al., 2015), with the intriguing possibility that they are

389 deleterious hitchhiker of fig wasps.

390 As we expected, the monoecious fig species, F. microcarpa, had considerably

391 lower numbers of nematodes within its figs than the gynodioecious F. hispida.

392 Increased nematode prevalence may be due to distinct biological differences and

393 contrasting costs between these two breeding systems. Furthermore, F. microcarpus

394 was the only nematode found in F. microcarpa and M. guangzhouensis was the

395 dominant nematodes in F. hispida. For both Ficus species, higher rates of nematode

396 infection were found in the rainy season when compared to the dry-hot season and

397 the inter-floral phase than the receptive phase of figs.

398 Nematodes are thought to be specific to fig species (Vovlas et al. 1992), with 
399 fossil records indicating a long history of co-evolution between nematodes and fig 400 wasps (Poinar 2003). However, Davies et al. (2010) and Zeng et al. (2007) showed 401 that one Schistonchus nematode species might live in multiple fig tree hosts. Some 402 nematodes are associated with more than one wasp species in Australia and Indonesia 403 (Davies et al. 2010, Sriwati et al. 2017). These generalist Schistonchus nematodes are 404 not restricted to the same wasp genus or Ficus subgenus/sections. Davies et al. (2011) 405 sampled 16 morphospecies of Schistonchus nematodes from 13 Ficus species. These 406 Ficus species were from subgenera Ficus, Sycomorus, and Urostigma and their 407 pollinating fig wasps from 5 different genera, Kradibia, Ceratosolen, Eupristina, 408 Pleistodontes, and Platyscapa. Although Schistonchus nematodes were mostly 409 associated with Ficus species there is limited evidence to support species level 410 specificity. Therefore, host tree identity is not a reliable ecological trait for nematode 411 classification (Davies et al. 2015). Zeng et al. (2007) reported two nematode species 412 living in F. hispida in Guangzhou, China that differ from the species in F. hispida in 413 India, showing regional difference in nematode occurrence. There are about 800 414 Ficus species (Berg 1989) and approximately 67 of these species is found in Yunnan 415 province China (Zhang and $\mathrm{Wu} 2004$ ). Thus, nematode species diversity is likely 416 high in Yunnan based on fig tree diversity (but see the above discussion on host 417 specificity). Further study of the classification, phylogeny, and ecology of nematodes 418 is required to confirm these assertions.

419 Nematode prevalence was higher in the rainy season than in the hot-dry season 
420 for both F. hispida and F. microcarpa, indicating high temperature and humidity is

421 important for nematode development. In this case breeding system appears to have

422 limited explanatory power, suggesting a similar phenology and dispersal regime

423 between the study species. Nematode numbers were higher in the $\mathrm{C}$ phase figs than

424 the B phase in both species, which indicates that nematode development continues

425 alongside that of figs. However, no differences in nematode abundance were found

426 between male and female figs of $F$. hispida, which implies that nematode

427 development is not reliant on fig wasp presence because no fig wasps develop in

428 female figs. Over ten lineages of nematodes have been reported to be associated with

429 figs, some of them are thought derived from fungal feeders (Davies et al., 2015),

430 others are plant parasites (Davies et al., 2009), bacterial feeders (Kanzaki et al., 2016),

431 or entomophagous (Herre, 1995; Ramírez-Benavides \& Salazar-Figueroa, 2015; Van

432 Goor et al., 2018). Ficophagus and Martininema nematodes were included in these new

433 genera after being split from Schistonchus (Davies et al., 2015). Nematodes in

434 Schistonchus have long been thought to feed on plant tissue (Center et al., 1999).

435 However, Ficophagus and Martininema are thought to be derived from aphelenchoidid

436 fungal feeders (Davies et al., 2015). The most well-known aphelenchoidid nematode is

437 the pinewood nematode, Bursaphelenchus xylophilus, this species is transported by

438 longhorn pine beetles. The nematode feeds on pine tissues and fungi, and causes pine

439 wilt disease (Futai, 2013; Zhao et al., 2013).

440 Since our focal nematodes may feed on fungi, knowledge on fungal diversity and 
441 species composition is essential for us to understand the life history and prevalence of 442 these nematodes. However, nothing is known about the fungal community in the figs 443 of China to date, despite the study by Martinson et al. (Martinson et al., 2012) in Panama. 444 Are these fungi plant pathogens or are they insect necrophages? Because fungal growth 445 is sensitive to temperature, we suppose that the fungal community within the figs will 446 vary across seasons. Seasonal variation in temperature will substantially affect the 447 development of figs, fig wasps, fungi and nematodes, and lead to both population and 448 community levels oscillations.

449 Nematodes must enter the abdomen of fig wasps for transmission to a new host. 450 Although, Krishnan et al. (2010) reported that Schistonchus nematodes could 451 distinguish female pollinating fig wasps from wingless male fig wasps and non452 pollinating fig wasps using chemical cues in F. racemosa. Van Goor et al (2018) 453 provided contrasting results, in their study system both pollinating and non454 pollinating fig wasps are infected by nematodes. While fig wasp assemblage size can 455 range between three and 30 species (Compton \& Hawkins, 1992) only certain wasps 456 are likely transport nematodes from one host to another (e.g. Agaonidae, Sycoecinae 457 and some Sycophaginae and Otitisellinae), because most non-pollinating fig wasps 458 do not enter into the syconium to oviposit. It is not known if non-pollinating fig 459 wasps are capable of transporting nematodes, and this would be an interesting area 460 for future research.

461 The nematodes transported by C. solmsi marchali, the pollinator of F. hispida 
at Xishuangbanna are not parasites of the insect, because their body lengths did not

463 increase when they entered into the abdomens of fig wasps. These results indicate

464 that nematodes did not absorb the nutrients of wasps and only used the pollinator female

465 for transmission. This conclusion is also supported by the fact that their close relatives

466 are fungal feeders. Moreover, the nematodes did not hinder the capacity of fig wasps

467 to carry pollen and eggs. It has been hypothesized that phoretic nematodes have

468 detrimental effects on fig wasps by reducing pollen grains or egg loads (Davies et al.,

469 2015). Our results do not support this hypothesis, possibly because pollinating fig

470 wasps are pro-ovigenic, with egg number likely being determined during

471 development rather than in the adult stage (Elias et al., 2018).

However, nematodes reduced the life span of pollinators and the wasps carrying

473 more nematodes were, therefore, less likely to reach receptive trees, which may result

474 in costs being inflicted on fig wasps by these nematodes. The number of nematodes

475 in the abdomen in those fig wasps that 'arrived' in the B phase figs to lay eggs and

476 pollinate was less than in newly emerged fig wasps, indicating that wasps with higher

477 nematode loads are less likely to reach figs and might die during this period. Herre

478 (1995) also reported that the proportion of nematode-infested fig-pollinating wasps

479 reaching receptive figs was reduced compared to nematode free wasps. Fig wasps are

480 small and short-lived insects, nematodes could be an encumbrance for them during the

481 process of host location, pollination, and oviposition. Filtering out severely infected

482 fig wasps may prevent the overexploitation by nematodes of next generation of fig- 
483 fig wasp, and thus stabilize the evolutionary coexistence of parasitic nematodes and 484 the fig-fig wasp mutualism.

485 The results of this study reflect the natural complexity of this system, suggesting 486 isolated, artificially controlled experiments may not reveal the relationship between 487 nematodes and fig wasps when the ecological background (e.g., the feeding mode, life 488 cycle, and relationships between Ficophagus and Martininema, figs and fig wasps) is 489 ignored. To better understand the effects of nematodes on the stability of the fig and 490 fig wasp mutualism, a cross-sectional analysis is not enough, and longitudinal studies 491 are required to give us the whole profile and the process of the influence of 492 nematodes on fig-fig wasp mutualism. The number of aborted figs, the abundance 493 and nematode species inside the aborted figs, and even the variation in fungal 494 community should be studied in the future. Network thinking is required and we 495 should treat the syconium as a whole, incorporating the interactions among figs, 496 pollinating fig wasps, the multi-species of non-pollinating fig wasps, nematodes, 497 fungi, and even bacteria in this enclosed ecosystem. 


\section{ACKNOWLEDGMENTS}

We are grateful to Dr. Natsumi Kanzaki for his technical support in collecting the

501 nematodes, and to Charlotte Jandér and Professor Edward Allen Herre for their

502 suggestions and comments on an early version of this manuscript. We are also give

503 thanks to two anonymous reviewers for their valuable comments and suggestions,

504 which greatly improve the quality of this paper. This research is funded by the National

505 Natural Science Foundation of China (31672373, 31600302, 31570418, 31770463,

506 31572252) and CAS 135 program (NO. 2017XTBG-T01). STS acknowledges

507 departmental funding from Harper Adams University.

508

509 Competing financial interests

$510 \quad$ The authors declare no competing financial interests.

\section{Author Contributions}

512

R. R. S., B. G. M., and Y. Q. P. designed and performed the study. Y. S. Z. identified

513 nematode species, B. W. analyzed the data, and R. R. S., S. T. S., B. W., and Y. Q. P.

514 wrote the main text of the manuscript. All the authors reviewed the manuscript. 


\section{References}

517 Bascompte J \& Jordano P (2007) Plant-animal mutualistic networks: The architecture 518 of biodiversity. Annual Review of Ecology Evolution and Systematics 38: 567519 593. doi:10.1146/annurev.ecolsys.38.091206.095818.

520 Borges RM (2015) How to be a fig wasp parasite on the fig-fig wasp mutualism.

521 Current Opinion in Insect Science 8: 34-40. doi:https://doi.org/10.1016/j.cois.2015.01.011.

Brooks ME, Kristensen K, van Benthem KJ, Magnusson A, Berg CW, Nielsen A, Skaug HJ, Maechler M \& Bolker BM (2017) Modeling zero-inflated count data

Cao M, Zou X, Warren M \& Zhu H (2006) Tropical forests of Xishuangbanna, China. Biotropica 38: 306-309. doi:10.1111/j.1744-7429.2006.00146.x.

Center BJ, Giblin-Davis RM, Herre EA \& Chung-Schickler GCJJoN (1999) Histological comparisons of parasitism by Schistonchus spp.(Nemata: Aphelenchoididae) in neotropical Ficus spp. Journal of Nematology 31: 393.

Davies K, Bartholomaeus F, Ye W, Kanzaki N \& Giblin-Davis RJN (2010) Schistonchus (Aphelenchoididae) from Ficus (Moraceae) in Australia, with description of S. aculeata sp. n. Nematology 12: 935-958.

Davies K, Ye WM, Giblin-Davis R \& Thomas WK (2009) Ficotylus congestae gen. n., sp n. (Anguinata), from Ficus congesta (Moraceae) sycones in Australia. Nematology 11: 63-75. doi:10.1163/156854108x398426.

Davies KA, Ye W, Kanzaki N, Bartholomaeus F, Zeng Y \& Giblin-Davis RM (2015) A review of the taxonomy, phylogeny, distribution and co-evolution of Schistonchus Cobb, 1927 with proposal of Ficophagus n. gen. and Martininema n. gen. (Nematoda: Aphelenchoididae). Nematology 17: 761-829. 
Measuring the discrepancy between fecundity and lifetime reproductive success in a pollinating fig wasp. Entomologia Experimentalis Et Applicata 140: 218225.

Dunn DW, Segar ST, Ridley J, Chan R, Crozier RH, Yu DW \& Cook JM (2008a) A role for parasites in stabilising the fig-pollinator mutualism. Plos Biology 6: e59.

Dunn DW, Yu DW, Ridley J \& Cook JM (2008b) Longevity, early emergence and body size in a pollinating fig wasp - implications for stability in a fig-pollinator

Elias LG, Lino-Neto J \& Pereira RAS (2018) Oogenesis and ovarian morphology in pollinating and non-pollinating fig wasps: evidence from adult and immature stages. Invertebrate Reproduction \& Development 62: 162-168. doi:10.1080/07924259.2018.1469549.

Futai K (2013) Pine Wood Nematode, Bursaphelenchus xylophilus. Annual Review of Phytopathology 51: 61-83. doi:10.1146/annurev-phyto-081211-172910.

Galil J \& Eisikowitch D (1968) On the pollination ecology of Ficus sycomorus in East Africa. Ecology 49: 259-269.

Giblin-Davis RM, Center BJ, Nadel H, Frank JH \& Ramírez B W (1995) Nematodes associated with fig wasps, Pegoscapus spp. (Agaonidae), and syconia of native Floridian figs (Ficus spp.). Journal of Nematology 27: 1-14.

Herre EA (1995) Factors affecting the evolution of virulence: Nematode parasites of fig wasps as a case study. Parasitology 111.

Herre EA (1996) An overview of studies on a community of Panamanian figs. Journal of Biogeography 23: 593-607.

Herre EA, Knowlton N, Mueller UG \& Rehner SA (1999) The evolution of mutualisms: exploring the paths between conflict and cooperation. Trends in Ecology \& Evolution 14: 49-53. doi:https://doi.org/10.1016/S0169$5347(98) 01529-8$. 
Janzen DH (1979) How to be a Fig. Annual Review of Ecology and Systematics 10: 13-51. doi:DOI 10.1146/annurev.es.10.110179.000305.

Kabacoff RI (2010) R in action: Data analysis and graphics with R. Manning Publications Co., Shelter Island, NY.

\section{Kanzaki N, Giblin-Davis RM, Ye W, Herre EA \& Center BJJN (2016)} Recharacterisation of three Parasitodiplogaster species based on morphological and molecular profiles. Nematology 18: 417-437. doi:10.1163/1568541100002967.

Kerdelhue C, Rossi J \& Rasplus J (2000) Comparative community ecology studies on old world figs and fig wasps. Ecology 81: 2832-2849.

Kong Y, Wang R, Yang D-R, Sreekar R, Peng Y-Q \& Compton SG (2016) Nonpollinator fig wasp impact on the reproductive success of an invasive fig tree: why so little? Biocontrol Science and Technology 26: 1432-1443. doi:10.1080/09583157.2016.1214862.

Krishnan A, Muralidharan S, Sharma L \& Borges RM (2010) A hitchhiker's guide to a crowded syconium: how do fig nematodes find the right ride? Functional Ecology 24: 741-749.

Lee CT (2015) Inherent demographic stability in mutualist-resource-exploiter interactions. American Naturalist 185: 551-561. doi:10.1086/680228.

Martin GC, Owen AM \& Way JI (1973) Nematodes, figs and wasps. Journal of Nematology 5: 77-78.

Martinson EO, Herre EA, Machado CA \& Arnold AEJMe (2012) Culture-free survey reveals diverse and distinctive fungal communities associated with developing figs (Ficus spp.) in Panama. Microb Ecol 64: 1073-1084. doi:10.1007/s00248012-0079-x.

Peng YQ, Yang DR \& Wang QY (2005) Quantitative tests of interaction between pollinating and non-pollinating fig wasps on dioecious Ficus hispida. Ecological Entomology 30: 70-77. doi:10.1111/j.0307-6946.2005.00650.x. 
600

601

602

603

604

605

606

607

608

609

610

611

612

613

614

615

616

617

618

619

620

621

622

623

624

625

626

627

Poinar G \& Herre E (1991) Speciation and adaptive radiation in the fig wasp nematode, Parasitodiplagaster (Diplogasteridae : Rhabditida) in Panama. Revue de Nématologie 14: 361-374.

R Development Core Team (2018) R: A language and environment for statistical computing: by RFfS Computing) R Foundation for Statistical Computing, Vienna, Austria., Vienna, Austria.

Ramírez-Benavides W \& Salazar-Figueroa L (2015) Parasitodiplogaster citrinema is an internal necrophagous species of the pollinating fig wasp Pegoscapus tonduzi. Nematology 17: 733. doi:https://doi.org/10.1163/15685411-00002906.

Sachs JL \& Simms EL (2006) Pathways to mutualism breakdown. Trends in Ecology \& Evolution 21: 585-592. doi:DOI 10.1016/j.tree.2006.06.018.

Simón-Porcar VI, Santos-Gally R \& Arroyo J (2014) Long-tongued insects promote disassortative pollen transfer in style-dimorphic Narcissus papyraceus (Amaryllidaceae). Journal of Ecology 102: 116-125. doi:10.1111/13652745.12179 .

Staniland L (1954) A modification of the Baermann funnel technique for the collection of nematodes from plant material. Journal of helminthology 28: 115118.

Sun F, Henry N \& Yu Q (2017) First report of the fig cyst nematode, Heterodera fici Kirjanova, on fig tree, Ficus carica, in Ontario, Canada. Journal of Nematolopgy 49: 131-132.

Susoy V, Herrmann M, Kanzaki N, Kruger M, Nguyen CN, Rödelsperger C, Röseler W, Weiler C, Giblin-Davis RM \& Ragsdale EJ (2016) Large-scale diversification without genetic isolation in nematode symbionts of figs. Science advances 2 : e1501031.

Terry MT (2015) A Package for Survival analysis in S.

Therneau T, M. (2015) A Package for Survival Analysis in S.

Van Goor J, Piatscheck F, Houston DD \& Nason JD (2018) Figs, pollinators, and 
parasites: A longitudinal study of the effects of nematode infection on fig wasp fitness. Acta Oecologica 90: 140-150. doi:10.1016/j.actao.2018.03.007.

Wang B, Segar ST, Deng G-Z, Luo T-X, Lin H \& Peng Y-Q (2019a) Variation in trophic cascade strength is triggered by top-down process in an ant-wasp-fig system. Oikos 128: 185-195. doi:10.1111/oik.05653.

Wang R, Chen X-Y, Chen Y, Wang G, Dunn Derek W, Quinnell Rupert J \& Compton Stephen G (2019b) Loss of top-down biotic interactions changes the relative benefits for obligate mutualists. Proceedings of the Royal Society B: Biological Sciences 286: 20182501. doi:10.1098/rspb.2018.2501.

Wang RW \& Sun BF (2009) Seasonal change in the structure of fig-wasp community and its implication for conservation. Symbiosis 47: 77-83. doi:10.1007/BF03182290.

Weiblen GD (2002) How to be a fig wasp. Annual Review of Entomology 47: 299330.

Wiebes J (1979) Co-evolution of figs and their insect pollinators. Annual Review of Ecology and Systematics 10: 1-12.

Zar JH (1999) Biostatistical analysis. Fourth edn. Prentice-Hall, Inc., Upper Saddle River, New Jersey.

Zeileis A \& Hothorn T (2002) Diagnostic Checking in Regression Relationships. R News 2: 7-10.

Zeng Y, Giblin-Davis RM \& Ye W (2007) Two new species of Schistonchus (Nematoda: Aphelenchoididae) associated with Ficus hispida in China. Nematology 9: 169-187.

Zeng Y, Ye W, Giblin-Davis RM, Li C, Zhang S \& Du Z (2011) Description of

652 Schistonchus microcarpus n. sp. (Nematoda: Aphelenchoididae), an associate of Ficus microcarpa in China. Nematology 13: 221-233.

Zhao L, Lu M, Niu H, Fang G, Zhang S \& Sun J (2013) A native fungal symbiont facilitates the prevalence and development of an invasive pathogen-native vector 

symbiosis. Ecology 94: 2817-2826. doi:doi:10.1890/12-2229.1.

657 Zuur AF, Ieno EN, Walker NJ, Saveliev AA \& Smith GM (2009) Mixed effects model 658 and extension in ecology with R. Springer Science+Business Media, New York. 659 660 
662 Figure 1. Mean percentage of nematodes prevalence in two Ficus species and

663 between female and male $F$. hispida. *** represent $\mathrm{p}<0.001$, ns represents non664 significant contrasts.

665 Figure2. Box plot of the number of nematodes per fig fruit in Ficus microcarpa 666 (a) and F. hispida (b) in the hot-dry and rainy seasons in Xishuangbanna. Each circle 667 represents a data point. $* * *$ indicates $\mathrm{p}<0.001$.

668 Figure 3. Box plot of the number of nematodes per fig fruit in Ficus microcarpa 669 (a) and F. hispida (b) in the B phase and C phase. Each circle represents a data point. $670 * * *$ indicates $\mathrm{p}<0.001$.

671 Figure 4. Box plot of the number of nematodes per fig wasp in different life 672 stages. Each circle represents a data point. Pairwise comparisons using the Tukey 673 contrasts: different letters represent significant differences between groups.

674 Figure 5. Kaplan-Meier survival curves of nematode-infested and nematode675 free pollinating fig wasps. 


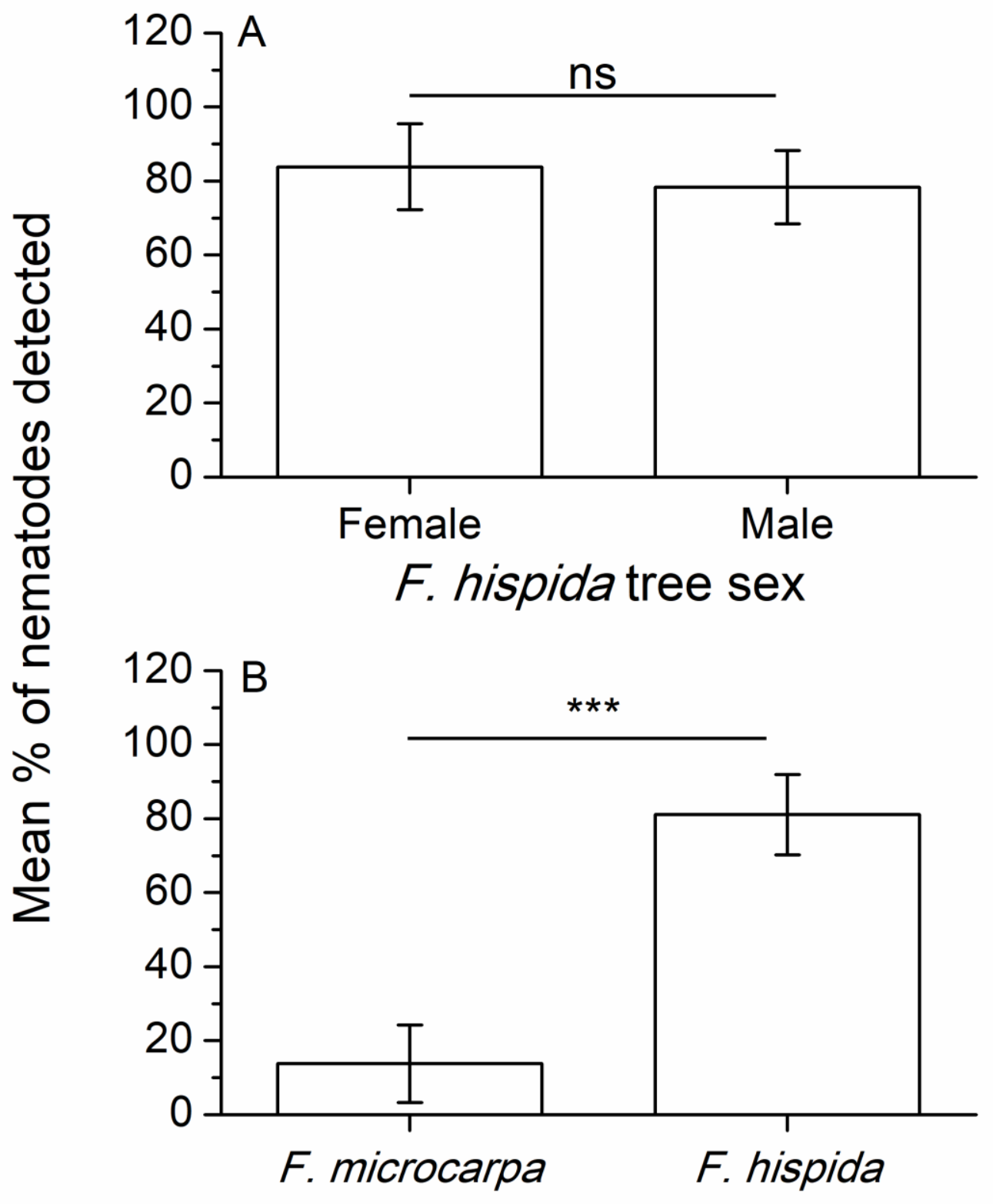

Ficus species 


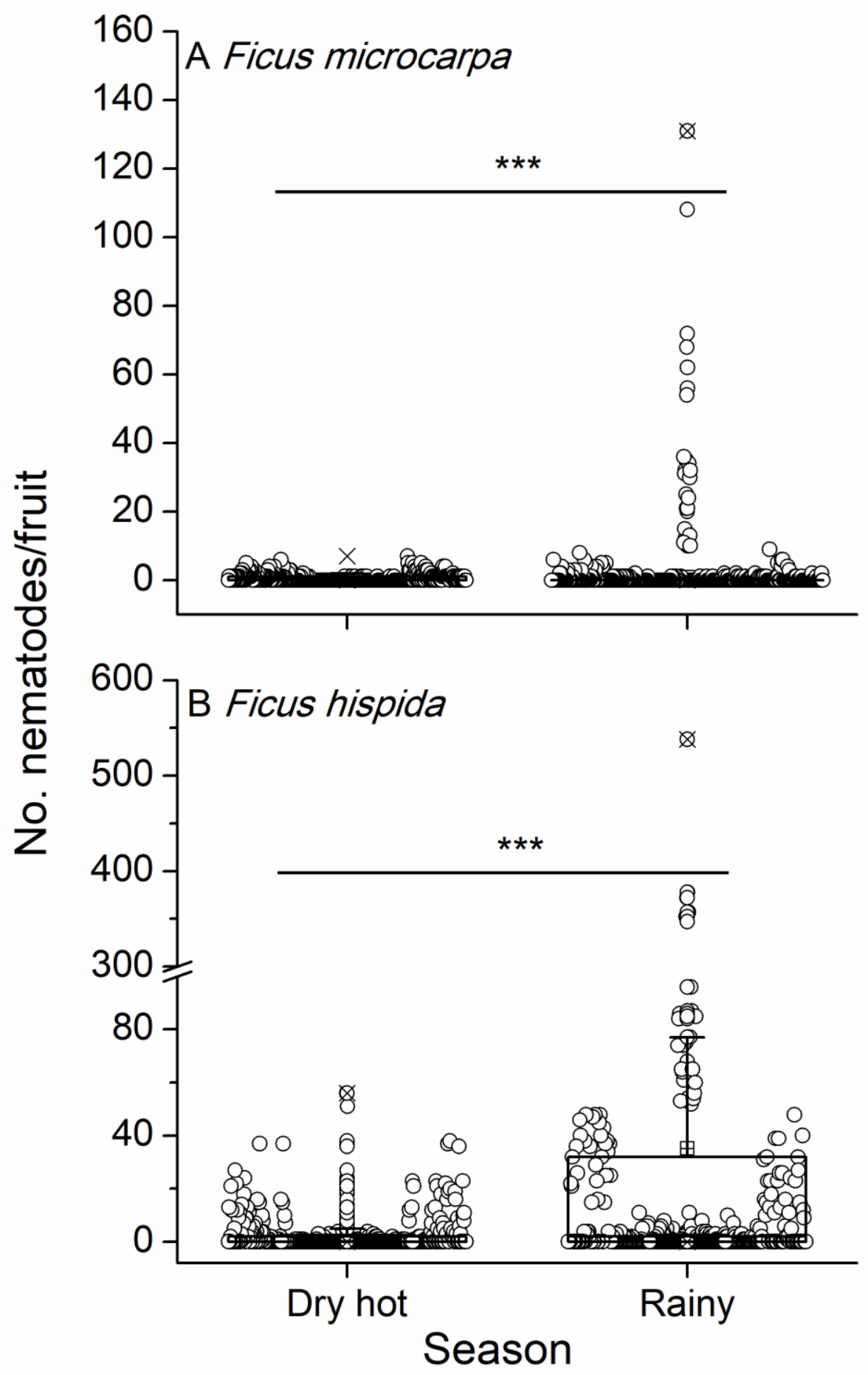

3 


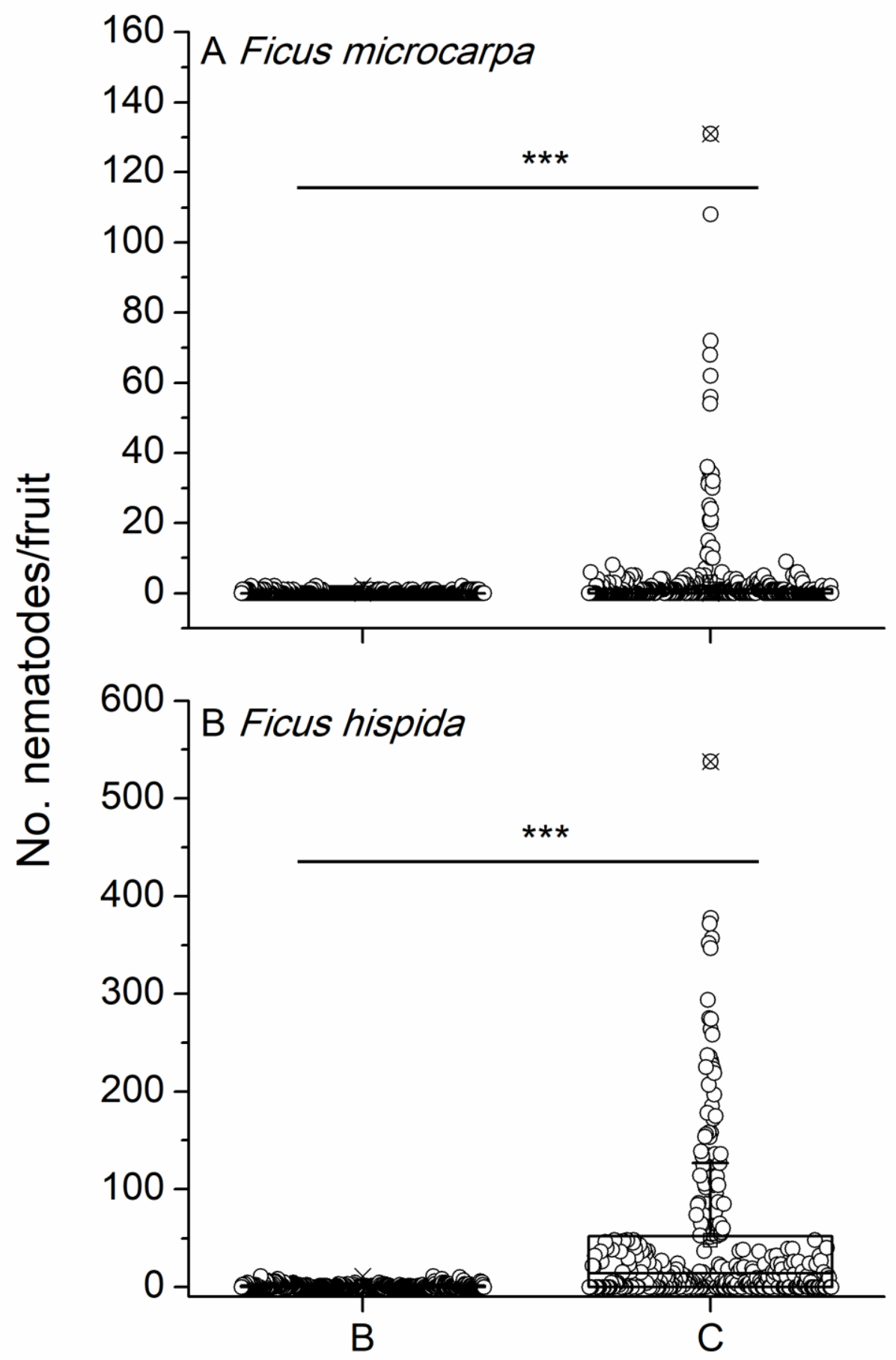

Fig developmental phase 


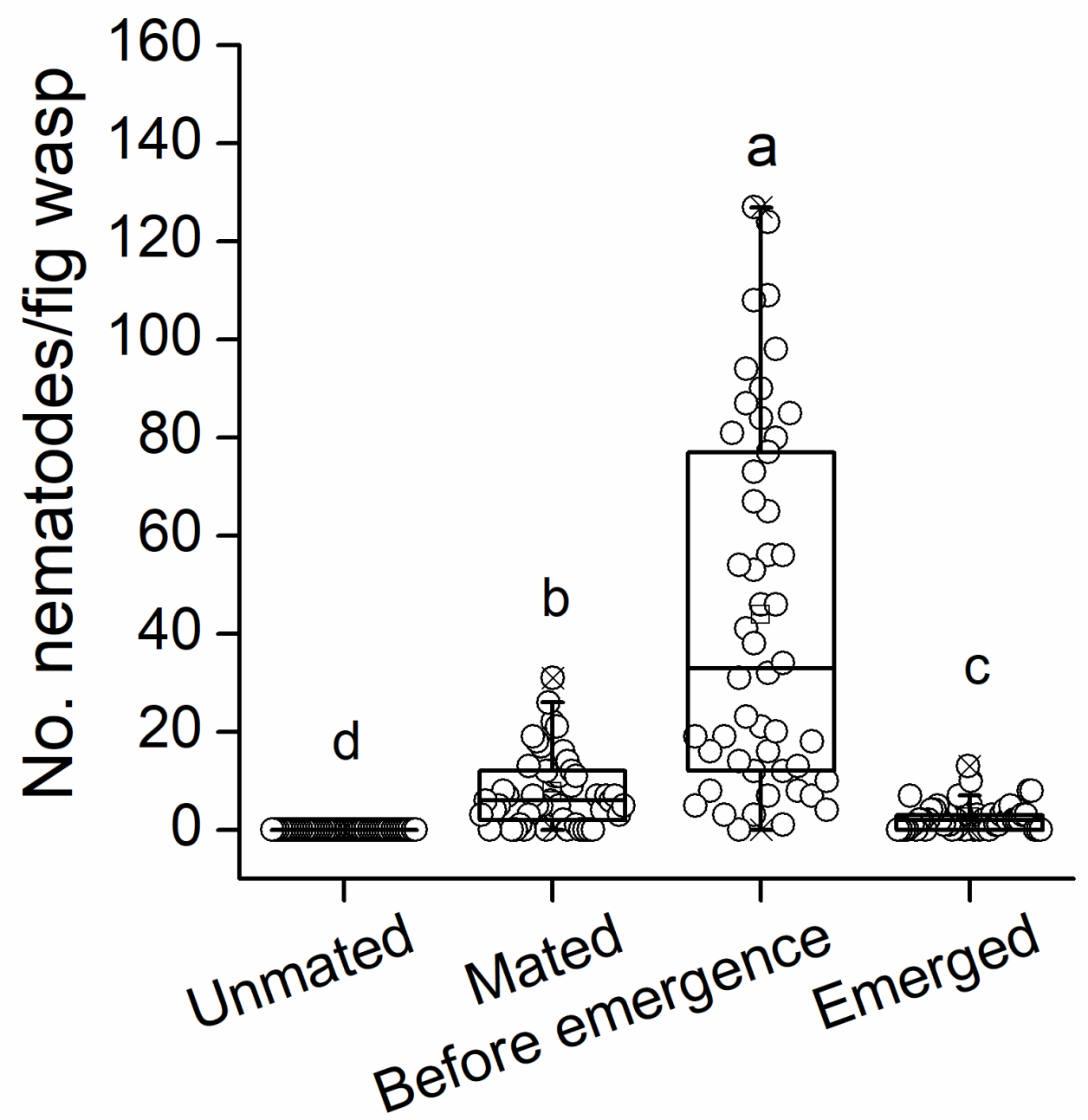




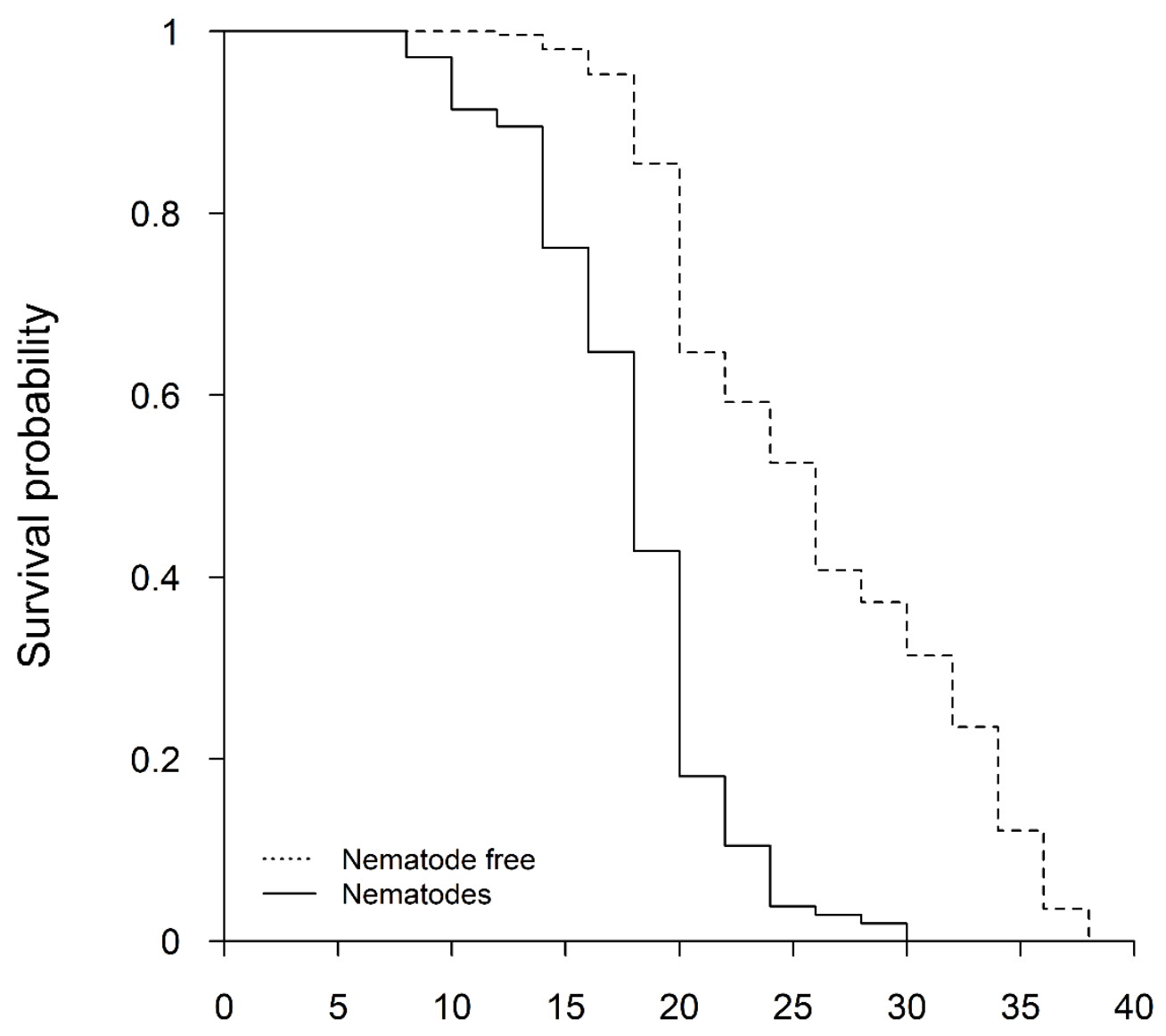

Fig wasp survival time in hours

13 
Table 1. Descriptive statistics of nematodes number in Ficus microcarpa and Ficus hispida across different seasons, fig sex, and

2 developmental phases in Xishuangbanna.

\begin{tabular}{|c|c|c|c|c|c|c|}
\hline Category & \multicolumn{3}{|c|}{ Levels } & Mean & SD & Sample size \\
\hline \multirow{2}{*}{ F. microcarpa-season ${ }^{1}$} & \multicolumn{3}{|c|}{ Dry-hot } & 0.52 & 0.99 & 520 \\
\hline & \multicolumn{3}{|c|}{ Rainy } & 2.86 & 11.53 & 461 \\
\hline \multirow{2}{*}{ F. microcarpa-phase ${ }^{2}$} & \multicolumn{3}{|c|}{$\mathrm{B}$} & 0.12 & 0.35 & 500 \\
\hline & \multicolumn{3}{|c|}{$\mathrm{C}$} & 3.18 & 11.24 & 481 \\
\hline \multirow{4}{*}{ Interactions season $\times$ phase $^{*}$} & \multirow{2}{*}{\multicolumn{2}{|c|}{ Dry-hot }} & B & 0.065 & 0.26 & 245 \\
\hline & & & $\mathrm{C}$ & 0.93 & 1.20 & 275 \\
\hline & \multirow{2}{*}{\multicolumn{2}{|c|}{ Rainy }} & $\mathrm{B}$ & 0.17 & 0.42 & 255 \\
\hline & & & $\mathrm{C}$ & 6.18 & 16.68 & 206 \\
\hline \multirow{2}{*}{ Ficus $^{* * *}$} & \multicolumn{3}{|c|}{ F. hispida } & 19.44 & 55.69 & 713 \\
\hline & & microcarpa & & 1.62 & 8.02 & 981 \\
\hline \multirow{2}{*}{ F. hispida-season ${ }^{1, * * *}$} & \multicolumn{3}{|c|}{ Dry-hot } & 2.66 & 7.06 & 346 \\
\hline & \multicolumn{3}{|c|}{ Rainy } & 35.27 & 73.95 & 367 \\
\hline \multirow{2}{*}{ F. hispida-sex ${ }^{3, \text { ns }}$} & \multicolumn{3}{|c|}{ Male } & 21.3 & 54.9 & 357 \\
\hline & \multicolumn{3}{|c|}{ Female } & 17.6 & 56.5 & 356 \\
\hline \multirow{2}{*}{ F. hispida-phase $\mathrm{e}^{2, * * *}$} & \multicolumn{3}{|c|}{ B } & 0.79 & 1.55 & 440 \\
\hline & \multicolumn{3}{|c|}{$\mathrm{C}$} & 49.51 & 81.51 & 273 \\
\hline \multirow{3}{*}{ Interactions season $\times$ sex $\times$ phase $^{*}$} & \multirow{3}{*}{ Dry-hot } & \multirow{2}{*}{ Female } & B & 0.25 & 0.52 & 125 \\
\hline & & & $\mathrm{C}$ & 10.04 & 12.17 & 52 \\
\hline & & Male & $\mathrm{B}$ & 0.48 & 0.86 & 125 \\
\hline
\end{tabular}




\begin{tabular}{lllccc} 
& & $\mathrm{C}$ & 6.95 & 10.27 & 44 \\
\hline \multirow{3}{*}{ Rainy } & \multirow{3}{*}{ Female } & B & 1.13 & 2.13 & 96 \\
& & $\mathrm{C}$ & 67.43 & 101.90 & 83 \\
\cline { 3 - 6 } & \multirow{2}{*}{ Male } & $\mathrm{B}$ & 1.59 & 2.03 & 94 \\
& & $\mathrm{C}$ & 75.43 & 86.34 & 94 \\
\hline
\end{tabular}

3

$5 \quad$ Notes:

$6 \quad$ 1. Nematodes were collected in dry-hot and rainy seasons in Xishuangbanna.

7 2. Figs were collected during $B$ and $C$ phases.

8 3. Ficus hispida is gynodioecious species with female and male individuals were collected and Ficus microcarpa is monoecious.

$9 * * * \mathrm{p}<0.001, \mathrm{~ns}$, not significant. 